\title{
A Review About Preparation and Properties of Biochar and Application Fields in the Environment
}

\author{
Marwa F. Al Rawi ${ }^{a}$, Ghayda Y. Al Kindi ${ }^{b}$, Jwad K. Al Refaae ${ }^{c}$ \\ ${ }^{a, b}$ Civil Engineering Dept., University of Technology-Iraq, Alsina'a street, 10066 Baghdad, Iraq. \\ ${ }^{\mathrm{c}}$ Al-Musayyib Technical Institute, Babel, Iraq. \\ *Corresponding author Email: marwa.f.alrawi@gmail.com
}

\begin{tabular}{l}
\hline H I G H L I G H T S \\
- Review the different sources for preparing \\
biochar. \\
- Explanation of methods of preparation under \\
different pyrolysis conditions. \\
- Suitable for use as a soil treatment, and \\
successful as an active permeable barrier to \\
keep groundwater from pollutants. \\
- The use of biochar for processing complies \\
with the principles of sustainable \\
development because it adopts the use of \\
waste and recycling for its manufacture as \\
an effective excellent in the treatment \\
process and thus is environmentally safe and \\
cost-effective.
\end{tabular}

A R T I C L E I N F O

\begin{tabular}{l} 
Handling editor: Wasan I. Khalil \\
\hline Keywords: \\
Biochar \\
Temperature \\
Ground water \\
Permeable Reactive Barrier \\
Adsorption \\
\hline
\end{tabular}

\begin{abstract}
A B S T R A C T
Biomass' pyrolysis process is responsible for producing the biochar charcoal, this process does not incorporate the oxygen, and it is utilized as a soil enhancer for each one of the carbon sequestration, and soil health prospects. Biochar can be defined as a stabilized solid which is enriched with carbon and could remain in the soil for extended period of time. Biochar has been studied as a way of carbon sequestration, and it might be a way used for handling climate change and global warming. It happens due to the processes that are associated with pyrogenic carbon capturing and storages. This review is focused on an overview of biochar preparation and application in the environment, previous studies and Applications. Biochar is prepared from various organic materials such as miscanthus, switch grass, corn stover, and sugarcane bagasse. The method of preparation varies with different temperatures and the discharge of nitrogen gas used for a period of one hour not to mention thermal decomposition at different temperatures of heat $(500,600,700$ and $800 \mathrm{oC})$. The success of its use as a adsorbent material, and in treating the soil from heavy metals, its suitability for agriculture, and the treatment of the liquid leachate from solid waste down into the groundwater, in addition to the treatment of groundwater when the topography of the region differs.
\end{abstract}

\section{Introduction}

The term "biochar" is an English neologism from the late 20th century. Pre-Colombian Amazonians manufactured biochar via the process of smoldering organicbyproducts. This means the coverage ofburning biomasses with soil in trenches [1] or pits [2]. It is unknown if they are used intentionally the biochar for enhancing soil outcome. European settlers named it terra-pretade-Indio [2]. Following experiments and observations, a team of researchers working in French Guiana assumed the fact that the Amazonian earthworms Pontoscolexcorethrurus were the majorcontributor of fine-powdering and incorporating charcoal waste in the soil [3].

\section{Production}

Biochar is a charcoal-like product rich in carbon, in a regulated process named pyrolysis. The transformation of the organic matters of the agriculture and forest wastes by burning them produces this kind of charcoal. Although very similar to familiar charcoal material, biochar is processed by means of a particular method for reducing pollution and storing carbon safely. While pyrolysis of organic materials like woodychips, leaves, or dead plants, they are burned in the containing units with small amount of oxygen. At a relatively low temperature $\left(<700^{\circ} \mathrm{C}\right)[4]$.

When burning matters, they would release a restricted amount or no smoke. Organic material is transformed into biochar, which is a stabilizedversion of carbon which cannot escape easily into the air When the pyrolysis process is in progress. During 
pyrolysis, the heat or energy emitted could be collected and utilized as one of renewable energy sources. Biochar is far more effective. and safer in comparison with other types of charcoal when turning carbon to stable form. As a material which is environmentally friendly and low-cost.From the literature, adsorbents were prepared from environmentally friendly materials, such as [5] prepared pillared clay as an adsorbent from Iraqi clays, [6] prepared the adsorbent from tea leaves, while, [7] prepared adsorbent from a waste of tea. Figure (1) shows pyrolysis as a combustion stage [4].

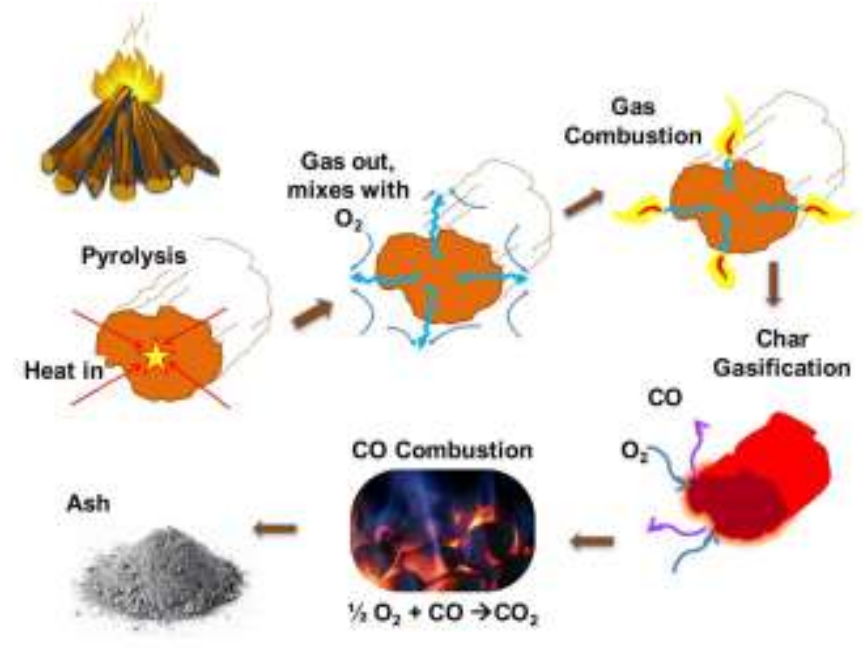

Figure 1: Pyrolysis as a phase of combustion [4]

\section{Pyrolysis Phases}

\subsection{Drying and Conditioning}

The majority of biomass has five main parts, in proportions depending on the source: hemicellulose, lignin, cellulose, water and minerals (ash).Seasoned wood on the cellulose / ligninstructure produces 12-19\% water adsorbed.

The water content of newly cut wood or agricultural wastesmay be ranging from $40-60 \% \mathrm{wb}$ (wet basisthat is expressed as a percent of the wet weighted of the biomasses). As the biomass is heated above $100^{\circ} \mathrm{C}$, much of the water is lost. The biomass begins to break down higher than $150^{\circ} \mathrm{C}$,then it starts to break down and soften at a temperature of approximately $150^{\circ} \mathrm{C}$ (referred to as conditioning). As with limited quantities ofvolatile organic compoundsamd $\mathrm{CO}_{2}$, chemically bounding water (from the composition of the biomass molecules) is emitted [4].

\subsection{Torrefaction}

When the biomassesare heated to the degree ranging from of $200-280^{\circ} \mathrm{C}$, the chemical bonding within the components of the biomasseswould be starting to set in break. This process involves an endothermic heat supply for increasing the dry biomass degree and breaks the molecular bonds.During this process, methanol, acetic acid, and other oxygenated Volatile-OrganicCompounds are released side-by-side with $\mathrm{CO}$, and $\mathrm{CO}_{2}$ releases from cellulose and hemicellulose breakdown. Torrefied biomassesis considered far more brittle than freshly produced biomasses, which is the thing that make the grinding such that used for the for boiler fuels, much easier and less energy demanding. It is highly resisting to water uptake, biological degradations, and enhancing storage. The liquid condensate of the vapor with low temperatures pyrolysis was named historically "wood-vinegar" or "smoke-water." It is also named as pyro ligneous acid, and as a flavoring agent utilized as "liquid smoke." It can be used as a seed germinating optimizer, fungicide, a plants growth helper, it also aids in stimulating composite and to increase the efficacy of biocharcoal, relaying on its concentrations and production temperatures [8].

\subsection{Exothermic Pyrolysis}

Thermal decompositions of the biomasses become highly intense of a temperatures 250 to $300^{\circ} \mathrm{C}$, according to the compositions of the feedstock, resulting in a combustible mixture of $\mathrm{CH}_{4}, \mathrm{CO}_{2}, \mathrm{H}_{2}, \mathrm{CO}$ and tarsandhydrocarbons. Pyrolysis is considered exothermic as energy is released by the breakdown of the broad biomass polymers. Some oxygen is found in biomass structure and is released, with the char and gases, enters into energy releasing oxidation reactions. The energy-released generates the heat required in the biomass for breaking more chemically formed bonds. This process is rendered to be selfsufficient in theory, as well as could proceed $400^{\circ} \mathrm{C}$ temperature with its own, leaving a residue similar to oxygen depleted, and carbon-enriched charcoal. Practically, heat generated from the pyrolysis area is lost, thus, exterior heat input is required during pyrolysis for increasing and then sustaining the temperatures. Prior to the final stage of the exothermic pyrolysis, the full yield is obtained, but the stable carbon content is relatively low. A wood biochar typically has an ash content of about $1.5-5 \%$, volatiles are about 25 _ $35 \%$ by weighting, and the balancing is fixed carbon at $60-70 \%$ [9].

\subsection{Endothermic Pyrolysis}

The biochar remains at the end of exothermic pyrolysis still containing large quantities of volatile matters. Moreheatis required by decomposing and driving off more of the volatiles for increasing the surface area, fixed carbon contents, and 
porosity. A temperature of $550-600^{\circ} \mathrm{C}$ giving about $80-85 \%$ of wood biochar's standard fixed carbon content and about $12 \%$ volatile content. At this temperature, wood biochar yields around $25 \_30 \%$ of the oven dry feedstock weight.

\subsection{Activation and Gasification}

Adding small quantities of steam and air would be increasing the surface temperature of the biochar to $700-800^{\circ} \mathrm{C}, \mathrm{Once}$ the temperature is more $600^{\circ} \mathrm{C}$ a couple of two processes will begin:

1. Activation. The biochar's surface can be activated by air, steam and heat and release more volatiles. By adding acidic functional groups, this could be increasing the surface region, and cation exchange of biochar's back and forth decrease in yield.

2. Gasification. The process is referred to as gasification is much more air and/or steam is applied.This will create a somehow clean gas that could be utilized to producepower. The biochar yielding is poor (usuallylessthan 20\%) and the ashes content high[10].

\section{Pre-Processing to Enhance Biochar Properties}

The pace at which the pyrolysis of the feedstock, and the lastcharacteristics of the biochar could be changed by biomass preprocessing, techniques that can include:

1. Pre-treating phosphoric acid biomasses to boost functional sets, decrease $\mathrm{pH}$, and create a slow release phosphatesfertilizer.

2. To soften the biomasses, i.e. break down lignocellulose compounds, pre-treating biomasses with alkali such as the potassium hydroxide.

3. Pre-treat the biomasses to create a magnetic biochar with Fe salts, for example removing heavy water and metals.

4. To slow the pyrolysis' rate, boosting $\mathrm{N}$ captures, and increasing the concentrations of nutrient-rich nanoparticle.

5. The surface, combine clay, salts (e.g. ferrous sulphate) or other minerals such as rock phosphate with biomass.

6. Low-densitybiomassespelletiseor briquette to assist addressing and increasing biochar outcome.

Figure (2) shows the pyrolysis of a single particle and Figure (3) shows the visualizations of the fivepyrolysis' steps [11]

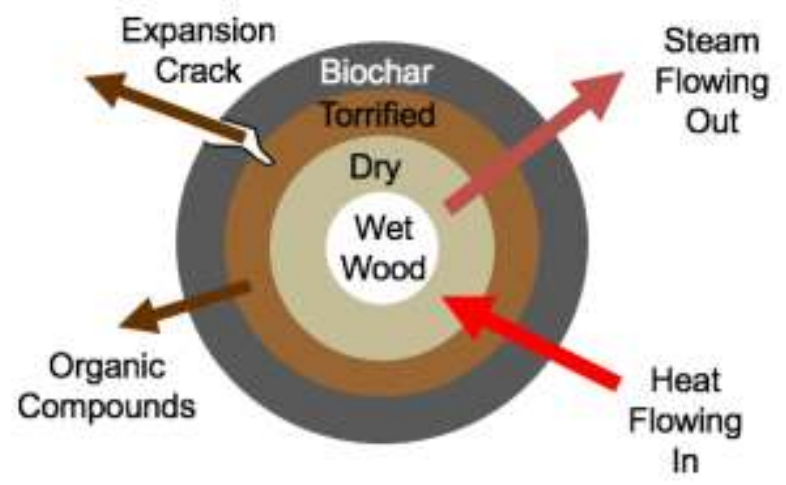

Figure 2: Pyrolysis of an individual particle[8]

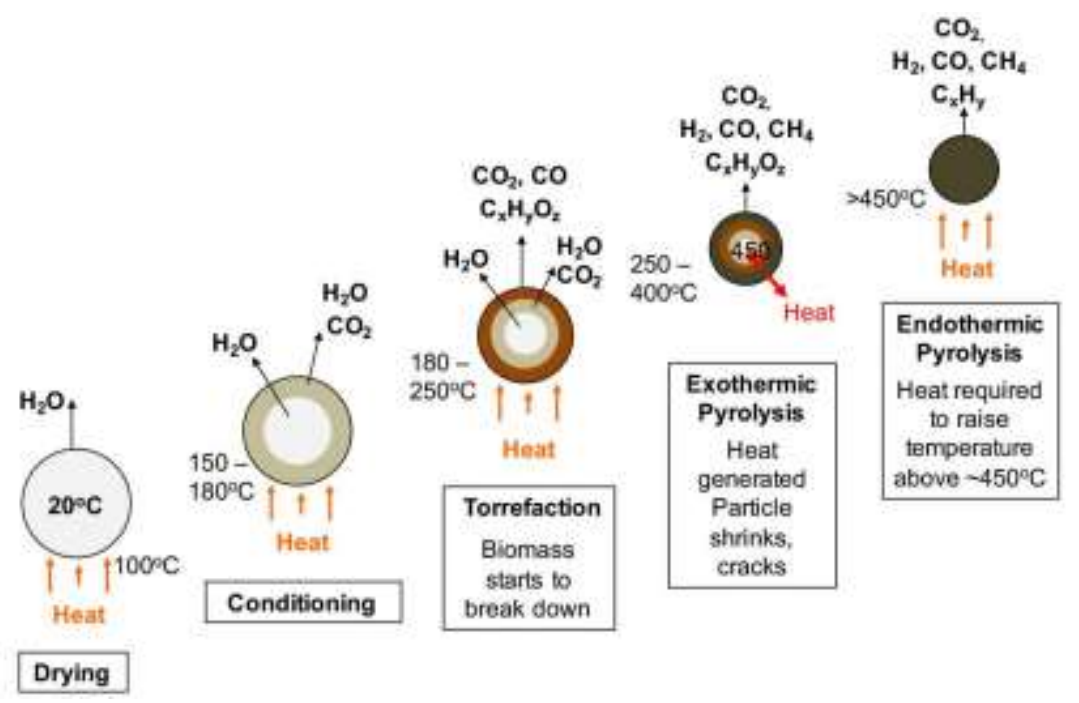

Figure 3: Visualization of the fivesteps of pyrolysis [11]

\section{Interaction Between Pyrolysis Time and Temperature}

Biochar could be produced in couple of seconds or over several days at different temperatures, according tothe size and form of feedstocks, that illustrated in Figure (4) [12]. 
There are risks to environmental as well as personal health and protection inherent in biochar processing.

Ensure protection of the operators of equipment and the general public

Minimizing atmospheric contaminant emissions Produce biochars suitable for a variety of particular applications [12].

\section{Material used for preparing biochar}

Flash torrefactionandcarbonization are other techniquesused for biomass transformation,

pyrolysis, hydrothermal carbonizations, and microwave carbonization are also options in addition to pyrolysis [13]. The flash-fire is ignited at a high pressures (1MPa-2MPa) on biomass packed bed during flash carbonization process to turn biomass to gas and solid phase products [13]. Around $40 \%$ of biomass is reported to be convertedat 1 MPa to solid phase products (biochar)[14]. Other pyrolysis techniques, such asplasma and laser crackmethods, have also been invented in addition to microwaves.

There is no sample use of laser pyrolysis technology and fast heating and cooling couldbeconducted, that effectively prevent secondary reactions from occurring [15]. In preparing coke and syngas, plasma pyrolysis technology is primarily applied. It can substantially increase syngas and minimize bio-oil yields compared to conventional cracking technology $[16,17]$. However, because of its high-cost, and energy consumption, the modern pyrolysis technology is difficult to popularize. These characteristics were shown in Table (1) [17].

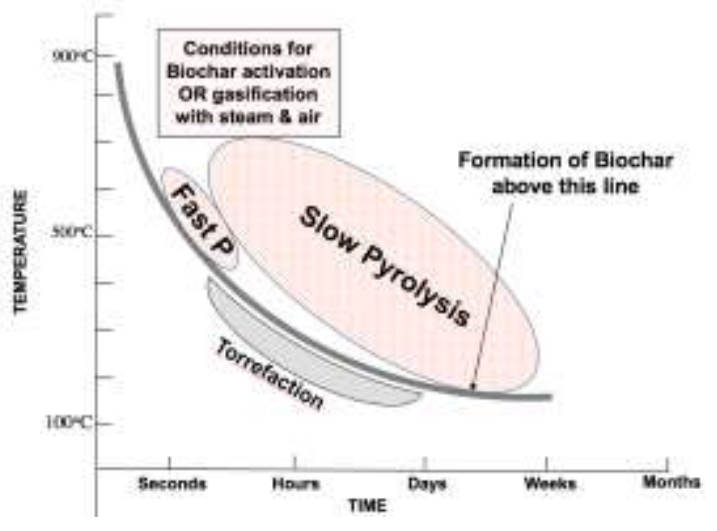

Figure 4: Relationship between temperature and time [12]

Table 1: Physico-chemical traits of biochar made by varioustechniques and process settings [17]

\begin{tabular}{|c|c|c|c|c|c|c|c|c|c|c|}
\hline Gaw Material & Atmosphere & $\begin{array}{c}\text { Trumperaturt } \\
\text { re }\end{array}$ & $\begin{array}{l}\text { Heatings } \\
\text { Mute } \\
\text { CClminin }\end{array}$ & $\begin{array}{l}\text { Residence } \\
\text { Time (h) }\end{array}$ & Vield (s) & $\mathrm{pH}$ & $\begin{array}{c}\text { Ash } \\
\text { Content } \\
\text { CSit }\end{array}$ & $\begin{array}{c}\text { Surface } \\
\text { Anes } \\
\left(\mathrm{m}^{2}-\mathrm{B}^{-1}\right)\end{array}$ & 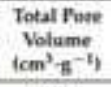 & $\begin{array}{l}\text { Puek } \\
\text { Dumetes } \\
\text { (num) }\end{array}$ \\
\hline \multirow{4}{*}{ Herb rosidtue } & & 400 & & & 579 & 102 & 283 & 942 & 0.042 & 139 \\
\hline & $\mathrm{N}_{2}$ & 600 & to & 3 & 312 & 10.1 & 311 & 513 & 0.051 & 390 \\
\hline & & $\$ 00$ & & & 20.1 & 106 & 34 & 703 & e.obs & $3 \times 9$ \\
\hline & & +60 & & & $35 \kappa$ & & $30 \pi$ & 52 & 0.1542 & \\
\hline \multirow{2}{*}{ Sname ietaw } & axyentintilud & 500 & 5 & 2 & $2 N 2$ & & 2544 & $\$ 6.4$ & oaghis & \\
\hline & & $\$ \infty 0$ & & & 224 & & $21 \%$ & $2 * 2$ & 0.433 & \\
\hline Corn straw & $\mathbf{S}_{\mathbf{y}}$ & 600 & & 3 & & 100 & 502 & 61.8 & 2006 & 207 \\
\hline Pline cons & $\mathrm{N}_{\mathrm{z}}$ & 500 & & 1 & & $4+6$ & 213 & 66 & 0.056 & \\
\hline Parathak & & $450-500$ & & & & 70 & 422 & 34 & Dass & \\
\hline \multirow{2}{*}{ Hidikory wood } & & 450 & & & $2 \times 5$ & 7.4 & 647 & 125 & & \\
\hline & $\mathrm{N}_{\xi}$ & $+\infty 0$ & 10 & 2 & 227 & 8.4 & 414 & 4010 & & \\
\hline \multirow{2}{*}{ Bugaser } & & iso & & & 250 & 7.5 & $236 \times$ & 236 & & \\
\hline & $N_{2}$ & 600 & 10 & 2 & 365 & 75 & 1536 & 3083 & & \\
\hline \multirow[b]{2}{*}{ Flamber } & & 460 & & & 263 & is & 5.53 & $b_{0.2}$ & & \\
\hline & $N_{z}$ & 600 & to & 2 & 240 & 92 & $11 \times 6$ & 3055 & & \\
\hline \multirow{2}{*}{$\begin{array}{c}\text { Noplar chipr } \\
\text { Burcucumber } \\
\text { plants }\end{array}$} & $\mathrm{N}_{2}$ & sकio & 5 & 2 & 218 & & 756 & 21258 & 0.18 & a.so \\
\hline & axym-lienited & 700 & 7 & 2 & 2752 & 12.23 & as. 72 & 231 & 0.008 & $67 \times 3$ \\
\hline Mine wand & $\mathrm{N}_{2}$ & $+\infty 00$ & ii) & 1 & & & 402 & 3996 & $a 003$ & \\
\hline \multirow{2}{*}{ Orangepped } & uxverntimithd & $\infty \infty 0$ & s & क & 113 & & 5,93 & 28.1 & 00409 & 2.9 \\
\hline & axygen-limithd & 700 & 3 & 6 & 5.93 & & 169 & 501 & $0 . \times 0$ & 16 \\
\hline $\begin{array}{l}\text { MLarine } \\
\text { macrailgae }\end{array}$ & $\mathrm{N}_{2}$ & 40 & y & 2 & & & & 105 & oan & 10.41 \\
\hline \multirow{3}{*}{$\begin{array}{l}\text { Municipal } \\
\text { solid waste }\end{array}$} & & $\$ 00$ & & 0.5 & & 80 & h. & n.7. & 0.08 & \\
\hline & $N_{2}$ & $3 \mathbf{0 0}$ & & as & & 85 & Q] & 29.1 & $000 y$ & \\
\hline & & $+\infty x$ & & es & & 90 & 6.2 & 205 & ences & \\
\hline \multirow{3}{*}{$\begin{array}{l}\text { Rice strais } \\
\text { Siwine manise } \\
\text { Auricularia } \\
\text { auricula dres }\end{array}$} & Axygen timitont & $7 \infty$ & & 2 & & & 58.47 & Je43 & 0.23 & \\
\hline & oxygen-limitnd & 700 & & 2 & & & 6073 & 2036 & 614 & \\
\hline & & 40 & & 2 & & & 0.5 & $\pi 64$ & a) & 4.837 \\
\hline Thulia dealbuta & $N_{i}$ & 500 & & 4 & & 1009 & 220 & 7.1 & & \\
\hline Constraw & $\mathrm{N}_{\mathrm{z}}$ & $\$ \infty$ & & 15 & & & 410 & Dess & ones & 501 \\
\hline
\end{tabular}

\section{Procedure for Preparation of Biochar}

Preparing biochar from namely miscanthus, switch grass, sugarcane bagasse, and corn Stover. Firstly grinding and drying under vacuum at $60^{\circ} \mathrm{C}$ all night long before pyrolysis and converted into. For avoiding any non-homogeneous behaviors throughout the pyrolysis, use a muffle furnace with three crucibles of same biomass at the same time. the required temperature is reached (with $20^{\circ} \mathrm{C} / \mathrm{min}$ heat ramps) subject to continues nitrogen gas for a period $2 \mathrm{~h}$, then, it is cooled at room temperature subject to continual nitrogen gas. The process was iterated at a variety of the pyrolysis temperature degrees $\left(500^{\circ}, 600^{\circ}, 700^{\circ}\right.$, 
and $800^{\circ} \mathrm{C}$ ). Secondly the biochars had undergone two-step on chemical activation: temperature and frequency are also low, and ultrasound activation followed by tetraethylenepentamime(TEPA) functionalization each item is indicated by a specific symbol, where namely (R) Raw,(US) Ultrasound Activated, (SG)Switch grass, (MS)Miscanthus, (SB)Sugarcane bagasse and (CS)Corn Stover,. Table (2) shows surface region analyses of raw and sono chemical activated biochar specimens that have been synthesized at various temperatures of pyrolysis [18].

Increasing the proportions of chemical elements due to an increase in the degree of pyrolysiswhere it increased $\% \mathrm{C}$ and $\%$ ashcontent with a shrinkage of $\% \mathrm{O}, \% \mathrm{H}$, and $\% \mathrm{~N}$ these changes become temperaturesranging from $500-700^{\circ} \mathrm{C}$.In addition, surface region and pores sizes were improved as well atincreasingheatformore than $700 \circ \mathrm{C}$. The entirety of these contributors played an additive role in the increment of adsorption ability. Surface region is remarkably influenced by thepyrolysis temperature and biochars feedstock [18].

Table 2: Surface regions analyses of raw and sono chemical activated biochars specimens made at various pyrolysis

\begin{tabular}{|c|c|c|c|c|c|}
\hline & \multirow{2}{*}{$\begin{array}{c}\text { Samples } \\
\text { pyrolysis } \\
\left.\text { temperatures }^{\circ} \mathrm{C}\right)\end{array}$} & \multicolumn{2}{|c|}{ Micro-porosity } & \multicolumn{2}{|c|}{ Micro-mesoporosity } \\
\hline & & $\begin{array}{c}\text { Surface } \\
\text { area }\left(\mathrm{m}^{2} / \mathrm{g}\right)\end{array}$ & $\begin{array}{c}\text { Pore } \\
\text { volume cc/g) }\end{array}$ & $\begin{array}{c}\text { Surface area } \\
\left(\mathrm{m}^{2} / \mathrm{g}\right)\end{array}$ & $\begin{array}{c}\text { Pore } \\
\text { volume }(\mathrm{cc} / \mathrm{g} \text { ) }\end{array}$ \\
\hline R-MS & 500 & 119 & 0.06 & 168 & 0.08 \\
\hline R-SG & 500 & 115 & 0.06 & 162 & 0.08 \\
\hline R-CS & 500 & 96 & 0.05 & 149 & 0.08 \\
\hline R-SB & 500 & 83 & 0.05 & 138 & 0.08 \\
\hline US-MS & 500 & 323 & 0.15 & 388 & 0.2 \\
\hline US-SG & 500 & 215 & 0.11 & 250 & 0.13 \\
\hline US-CS & 500 & 215 & 0.11 & 279 & 0.14 \\
\hline US-SB & 500 & 192 & 0.11 & 250 & 0.13 \\
\hline R-MS & 600 & 303 & 0.14 & 345 & 0.18 \\
\hline R-SG & 600 & 290 & 0.14 & 325 & 0.15 \\
\hline $\mathrm{R}-\mathrm{CS}$ & 600 & 284 & 0.14 & 293 & 0.14 \\
\hline $\mathrm{R}-\mathrm{SB}$ & 600 & 221 & 0.11 & 273 & 0.14 \\
\hline US-MS & 600 & 520 & 0.21 & 581 & 0.21 \\
\hline US-SG & 600 & 486 & 0.17 & 544 & 0.21 \\
\hline US-CS & 600 & 399 & 0.2 & 454 & 0.2 \\
\hline US-SB & 600 & 332 & 0.15 & 382 & 0.2 \\
\hline R-MS & 700 & 324 & 0.15 & 368 & 0.18 \\
\hline R-SG & 700 & 325 & 0.15 & 344 & 0.18 \\
\hline $\mathrm{R}-\mathrm{CS}$ & 700 & 298 & 0.14 & 308 & 0.14 \\
\hline R-SB & 700 & 236 & 0.12 & 289 & 0.14 \\
\hline US-MS & 700 & 532 & 0.12 & 588 & 0.21 \\
\hline US-SG & 700 & 520 & 0.21 & 570 & 0.21 \\
\hline US-CS & 700 & 423 & 0.2 & 473 & 0.21 \\
\hline US-SB & 700 & 352 & 0.18 & 400 & 0.2 \\
\hline R-MS & 800 & 316 & 0.14 & 390 & 0.2 \\
\hline R-SG & 800 & 311 & 0.14 & 351 & 0.18 \\
\hline R-CS & 800 & 288 & 0.14 & 357 & 0.18 \\
\hline R-SB & 800 & 240 & 0.12 & 290 & 0.14 \\
\hline US-MS & 800 & 526 & 0.21 & 576 & 0.21 \\
\hline US-SG & 800 & 503 & 0.21 & 550 & 0.21 \\
\hline US-CS & 800 & 407 & 0.2 & 452 & 0.2 \\
\hline US-SB & 800 & 358 & 0.18 & 403 & 0.2 \\
\hline
\end{tabular}

\section{Removing Mechanism of Main Pollutants by Biochars}

Biochar's soil contamination remediation mechanisms include ion exchange,physicaladsorption,complexation, electrostaticsinteraction, andprecipitation[19].

\subsection{Ion Exchange}

Ion exchanges is are the mechanism on the surfaces of acidic oxygen containing functional group.

Biochar like the carbonyl groups, hydroxyl groups, and carboxyl groups, can interact with ions of the heavy metal or the cationic organic pollutants by ionizing $\mathrm{H}^{+}$or surface base ions likeK $\mathrm{Kg}^{+}, \mathrm{Na}^{+}, \mathrm{Ca}^{2+}$, and so on[20].

\subsection{Physical Adsorption}

Physical adsorptions imply that BC utilizes its surface properties, namely porosity.

Big specific-surface regions such that contaminants like heavy metals organic compounds can be adsorbed or dispersed through the microspores on their surface.Theheavy metal ions'diameter is larger than the normal biochar pore-diameter. In general, the smaller the heavy metal diameter, the more the pores reach the biochar pores, thus increasing the ability of adsorption $[21,22]$. 


\subsection{Electrostatic Interaction}

The electro-static interaction signifies the electrostatic adsorption of biocharand heavy metal's ions between the surface loads.If the $\mathrm{pH}$ values of a solution is higher than the biochar (pHpzc) charging point, negative charged on the biochar surfaces was became ,aswell as the positive charged on heavy metal that cause electro-static adsorption. The heavy metal ions with positive charge on the biochar surface combine with the functional groups that contain oxygen like hydroxyl, carboxyl, and carbonyl $[23,24]$.

\subsection{Precipitation}

Biochar mineral components likeSO $4, \mathrm{SiO}_{3}, \mathrm{OH}, \mathrm{SO}_{3} \mathrm{CO}_{3}, \mathrm{PO}_{4}$, and $\mathrm{Cl}$ combined with heavy metal's ions for the formation of the water insoluble matters like metal phosphates, metal oxides, and metal carbonates that eases the immobilization and adsorption of heavy materials. The adsorption of $\mathrm{Zn}, \mathrm{Cu}$, and $\mathrm{Cd}$ by fertilizers biochars were majorly because of the $\mathrm{PO}_{4}$ and $\mathrm{CO}_{3}$ - precipitation, whereas the complexations of the electron's surface via - $\mathrm{OH}$ sets or delocalized $\pi$ has been minimized [25].

\subsection{Complexation}

Complexation means the interaction on the surface of biochars and heavy materials between oxygen containing functional sets to be forming complex that would be fixed [26]. The adsorptionsof tetracycline by biochar were majorly mediated by $\pi-\pi$ interaction and metal bridges, with the surface complexation as one of the key factors and cationic exchange force. It is often not a single mechanism in the adsorption process, however a hybridization of many mechanisms of adsorption [27].

\section{Biochar Characteristics}

\subsection{Chemical Characterization}

The original bio-mass feedstock and its biochar can go through a variety of tests to determine the essential physico-chemical characteristics of each raw and pyrolyzed material have been shown in Fig. (ㅁ) [28].

It has always been shown that chemical traits of single feedstock and thus of $\mathrm{BC}$ generated from feedstock differing remarkably both temporarily and spatially [28]. Production of $\mathrm{BC}$ is also evaluated by changes that may be occurring in elemental concentration of $\mathrm{H}, \mathrm{S}, \mathrm{C},, \mathrm{O}$, and $\mathrm{N}$ and related values [29].

Solid combustible residue which stays following carbonization of a particle sample and ejection of volatile material is known as fixed carbon [30,31]. It is therefore utilized as estimation of the number of the carbonaceous substances to be formed by a solid sample. In particular, as is usually defined in Van Krevelen diagrams, $\mathrm{O} / \mathrm{C}$ and $\mathrm{H} / \mathrm{C}$ ratios are utilized in order to evaluate the maturation and aromaticity degree [32]. On their latest work [33], where BC-based catalysts were used in canola oil transesterification, it was found that elemental analyses have shown a reduction in the ratios of $\mathrm{O} / \mathrm{C}$ and $\mathrm{H} / \mathrm{C}$ with an increase in pyrolysis temperature. It has been found that elemental $\mathrm{O} / \mathrm{C}, \mathrm{O} / \mathrm{H}$, and $\mathrm{C} / \mathrm{H}$ ratios provide reliable measures of the degree of pyrolysis as well as the amount of oxidative modification of $\mathrm{BC}$ in soil and solution systems, and are rather simple to calculate [34].

With a rise in carbon burn-off, despite pyrolytic temperature, the areas of BET (Brunauer, Emmett, and Teller) maximized [34]. This means that the carbon burn-off has the most important impact on the surface area's growth. In general, with pyrolytic temperature and residence time, the surface area, average pore size, and pore volume maximized [35]. The BET surfacesregion of BC $\left(1057 \mathrm{~m}^{2} / \mathrm{g}\right)$ that has been marginally greater than the value of $\mathrm{AC}\left(970 \mathrm{~m}^{2} / \mathrm{g}\right)$, was determined. The microporessize of $\mathrm{BC}(0.24 \mathrm{~mL} / \mathrm{g})$ has also been less than that of active carbon $(0.32 \mathrm{~mL} / \mathrm{g})$, reliably greater than the latter $(3.3$ $\mathrm{nm})$ with a mean pore's diameter of the former $(5.2 \mathrm{~nm})$ [36]. The magnetics $\mathrm{BC}$ for theorganic sorption compounds and phosphate worked extensively to establish that the surfacesregions (interior and exteriorsurfacesregions) of BCs were less than other BCs, despite of the fact that themean usage of the former pore radius was higher than the other one. This may be attributed to large amount of iron oxide present in the magnetic BCs, which have less surface regions and ample intermediate pores [37].

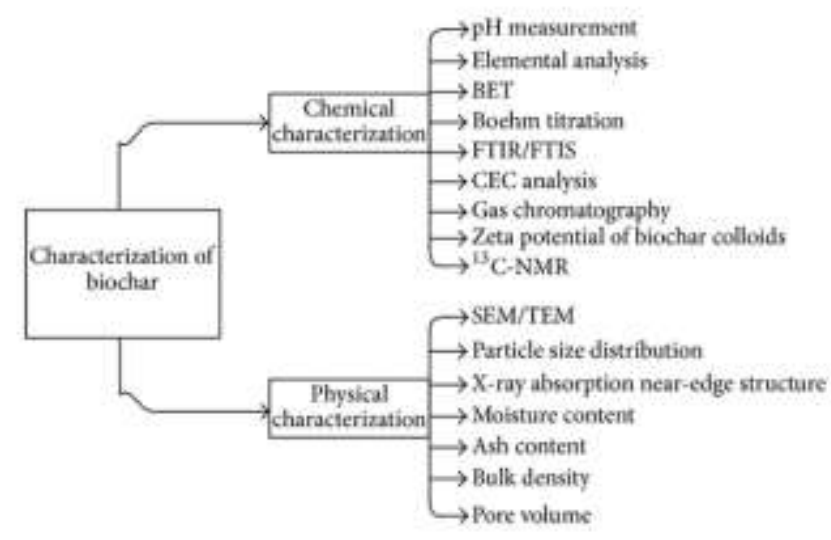

Figure 5: Overview of suggested biochars measurement methods [28] 
Operational determinations of the essential and acidic functional groups and on BC may be carried out by Boehm titration[38]. Where $\mathrm{BC}$ is balanced in existence of sequentially strong bases $(\mathrm{C}, \mathrm{HC}, \mathrm{OH}-$ and ethoxides) or strong acids ( $\mathrm{HCl}$, $\mathrm{H}_{2} \mathrm{SO}_{4}$, and $\mathrm{HNO}_{3}$ ), accompanied by a tight acidic or base extract titration for estimating the reacted fractions. Variations in the number of the bases or acids required are utilized (acidic equilibration) for estimating their relative quantities of the lactonic, phenolic, and carboxylic functional sets (base balance) or fundamental functionality [39]. BC characterization utilized as soil alteration and ethoxides' balance is excludedtypically as it tests functional sets dissociated merely atextremely higher $\mathrm{pH}$, whereas pollutant immobilizations occur at fairly low $\mathrm{pH}$ [37]. For hydrophobic BC, Boehm titration works well, but in the case where a large number of bio-oil types or mineral surfaces are present, a significant deficiency occurs[40]. There are 4 regions of transition usually observed under non-hydrothermal conditions in the carbonizations of biomass's feedstock for BC preparations [41]. They are including dehydration, nucleation of graphene,pyrolysis, and eventually carbonization.

These alterationscould be noticed,asBC is subject to Fourier transform infra-red spectroscopy (FTIS/FT-IR). The chemical functional sets presented on the BCC can also be identified by FTIS/FTIR again [42]. As enumerated by Lee etal., their recent work [43] had shown that samples characteristics of the bonds used in the preparation of gasification $\mathrm{BC}\left(700^{\circ} \mathrm{C}\right)$ and quick pyrolysis $\mathrm{BC}$ at $450{ }^{\circ} \mathrm{C}$ They were identicalto the cellulose ones.

It is evident that there is substantial decreasingof characteristics correlated with $\mathrm{O}-\mathrm{H}\left(3600 \mathrm{~cm}^{-1}-3100 \mathrm{~cm}^{-1}\right), \mathrm{C}=\mathrm{C}$ and $\mathrm{C}=$ $\mathrm{O}$ stretching $\left(1740 \mathrm{~cm}^{-1}-1600 \mathrm{~cm}^{-1}\right)$ and aromatic $\mathrm{C}=\mathrm{C}$ and $\mathrm{C}-\mathrm{H}$ deformation modes of the alkenes $\left(1500 \mathrm{~cm}^{-1}-1100 \mathrm{~cm}^{-1}\right)$ between base-line corrected FT-IR spectra of the sample as well as the C-O-C symmetric stretching $\left(1097 \mathrm{~cm}^{-1}\right)$ properties of the hemicelluloses and cellulose. In combined sorption of $\mathrm{Pb}^{+2}$ and its mechanism case study that has been performed by [42]. By the FT-IR spectra analyses of the sludge-derived BC, BC has been found to include an abundant carboxyl and hydroxyl groups (SDBC) amount. Again, after being substituted by the lead at a range of $1400 \mathrm{~cm}^{-1}-1500 \mathrm{~cm}^{-1}$, the complexed carboxyl (-COOMe) band does not show any simple change effect, likely as a result of the corresponding replacement of the cations. The important band change at $3404 \mathrm{~cm}^{-1}-3406 \mathrm{~cm}^{-1}(\mathrm{pH}=2), 3429 \mathrm{~cm}^{-1}(\mathrm{pH}=4), 3420 \mathrm{~cm}^{-1}(\mathrm{pH}=3)$, and $3422 \mathrm{~cm}^{-1}(\mathrm{pH}=5)$ assisted the proposed complexation between the functional groups $\mathrm{Pb}^{2+}$ and hydroxyl as well as carboxyl [44]. Furthermore, the band was moved to $1034 \mathrm{~cm}^{-1}(\mathrm{pH}=4)$ and $1035 \mathrm{~cm}^{-1}(\mathrm{pH}=5)$ at $1032 \mathrm{~cm}^{-1}$; they have concluded again that it was a sign of $\mathrm{Pb}^{2+}$ coordination with the groups of the carboxylate [44].

Cationic exchange capacity (CEC) as extensivelycalled agronomical sector represented the measurement of the surfaces charging in $\mathrm{BC}$ or soil, increasing with the aging of the $\mathrm{BC}$ ages [28] and was attributed to an increment in some oxygenated functional sets on surfaces of BC [37]. The highly distinct change in any absolute CEC value was noticed for BC as an outcome of time where it maximized by $278-518 \mathrm{mmole} \mathrm{kg}^{-1}$, most likely due to the fact that the oxidation process created carboxylic and hydroxyl acidic functional sets [45].

Biomasses feedstock is a main factor ruling the status of this physico-chemical characteristics; The most notable process parameter is pyrolytic temperature; carbon content of $\mathrm{BC}$ is not directly associated with the $\mathrm{BC}$ yielding, maximized from 53 $83 \%$, and from $300^{\circ}-800^{\circ} \mathrm{C}$ in one study, whereas theyieldingof $\mathrm{BC}$ incrementedby $67-26 \%$ [46].

\subsection{Physical Characterization}

The scanofelectron microscopy (SEM) is a microscopic method used to assess the macroporosity of images and physical morphology of solids [47]. BC's macroporoustoplology (pores of about $1 \mu \mathrm{m}$ diameter) formed from cellulose plant material depends on the feedstock's intrinsic architecture, and the water holding and adsorption capability of contaminants in soil and solution systems is potentially significant [47]. Figure 6 shows the BCCS (cotton (Gossypiumher baceum) straw) and BCPS (potato (Solanumtuberosum) straw) SEM micrographs obtained in our previous research [48]. Due to the fact that the existence of tubular structures originally originating from plant cells, the BCs formed at distinct pyrolytic temperatures had a distinctive honey-comb-like appearance. BCs had a high BET surface area as a consequence of these well-developed pores. The importance of pyrolytic temperature leads to the possibility that BC may be suitable for controlling the release of fertilizer nutrients produced at low pyrolytic temperature[49]. While high temperatures in environmental remediation would lead to a material similar to activated carbon [50].
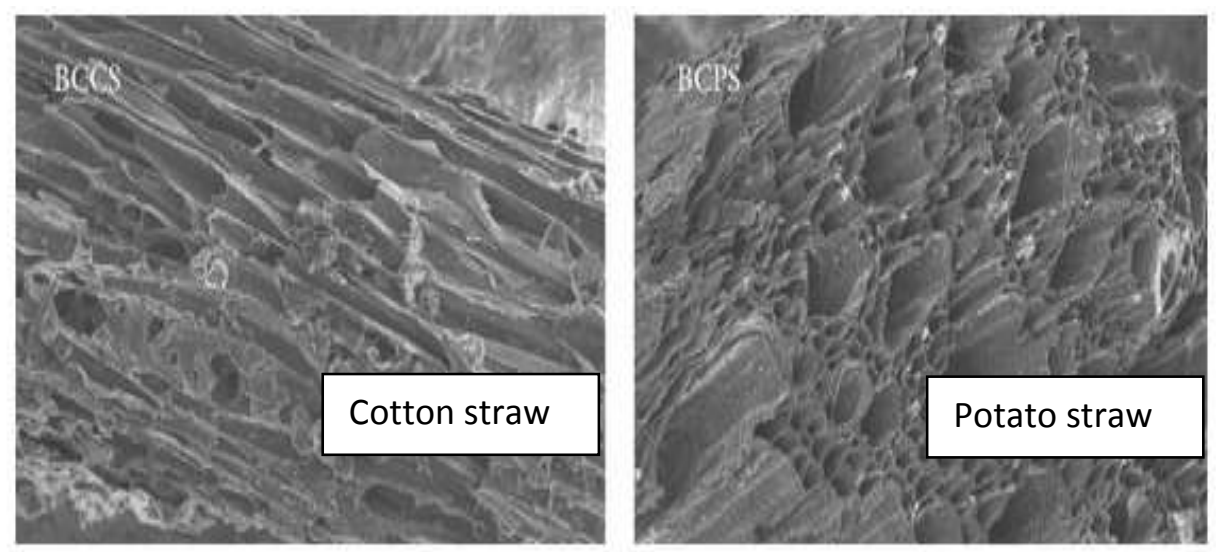

Figure 6: Photomicrograph from SEM [48] 


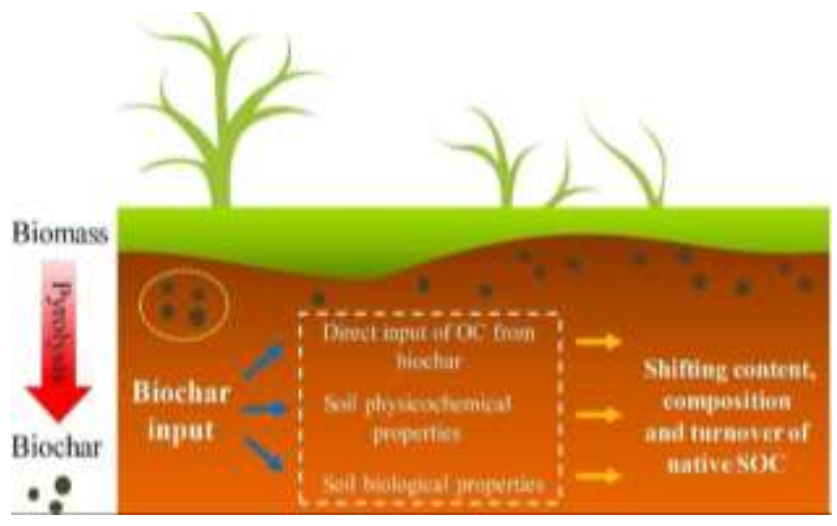

Figure 7: Biochar effect on soil and organic material

It can also be detected that BC low-temperature surfaces may be hydrophobic, whichcan decrease their ability to retain soil water as well as adsorb pollutants. The nature, quality, traits, and potential usage of BC may affect the shape, form, preliminary preparations steps and size of biomass's feedstock and kind of pyrolysis products. Initially, its size would influence the ratio of exposure to the BC's total surface area. In addition, while BC's low pyrolytic temperature is more powerful than products of higher temperatures, it is fragile and once integrated into the soil, pore is abrade into finer fraction[48].

Offered a vivid interpretation when describing the relation between the heavy metal's absorption mechanism and SEM [42]. In SEM photography, bright zones were observed on the porous surface of $\mathrm{Pb}$-loaded $\mathrm{BC}$ at $\mathrm{pH}=5$. Itsenergy dispersive $\mathrm{X}$-ray analysis(EDX)schedule reflects the red-surface, and also confirmed the presence of phosphorusas well as silicon, which could occur in the kind of precipitates of $5 \mathrm{PbO} \cdot \mathrm{P}_{2} \mathrm{O}_{5} \cdot \mathrm{SiO}_{2}$ (lead phosphate silicate) that has also been recognized bycalled(XRD)spectraTheysummarized that the precipitates can be a necessaryway of modeling the $\mathrm{Pb}^{2+}$ removal mechanism from the soil system, and that they could be connected to the solutions system again [51].

\subsection{Proximate analysis}

The approximate analysis was developed by the American Society for Testing and Materials Analysis Method (ASTM D1762-84) for wood charcoal analysis. This method has been used to assess the quality of biochar. A proximate analysis provides characteristic information concerning the material, which includes moisture, volatile matter, ash, and carbon content. The problem of this method the material exposure to oxygen and not well controlled on the moisture content and volatiles during the process.

Mitchell et al. [52] thermo-gravimetric analysis TGA was used for approximation analysis of BC. The moisture content has been calculated as a percentage of the sample mass lost between the temperature of the room and $100^{\circ} \mathrm{C}$, $\mathrm{VM}$ as a percentage of mass lost between $150^{\circ} \mathrm{C}-450^{\circ} \mathrm{C}$, Ash as a percentage of the residual mass after combustion is $750{ }^{\circ} \mathrm{C}$. During the TGA process, the samples have been heated under $\mathrm{N}_{2}$. Atmosphere to a temperature of $750^{\circ} \mathrm{C}$, the air has been introduced to the system and maintained for $5 \mathrm{~min}$. This method is used for a small sample size which reduces the accuracy of the analysis.

Enders et al [53] modified the procedure. The crucibles have been heated to a temperature of $750^{\circ} \mathrm{C}$, cooled to ensure the absence of moisture before the analysis, the moisture content in an atmosphere rich in argon which was determined as a lost mass at a temperature of $105^{\circ} \mathrm{C}$ for a period of $18 \mathrm{hrs}$. Determination of volatiles in an argon-free atmosphere after heating the oven to a temperature of $950{ }^{\circ} \mathrm{C}$. The percentage of ash content was determined as a mass residual at $750{ }^{\circ} \mathrm{C}$ after 6 hours in the air [54]. Increasing the temperature of thermal deformation, the volatile and biodegrades production time reduced because of the destruction of cellulose cracks [55]. Also increasing temperature during thermal dissolution increases the amount of volatile compounds within the molecule gradually [56]. Moreover, the increased ash content of BC makes it proper for absorbing phosphates and metal ions $[57,58]$. But, ash increases will weaken the ability to adhere to biological coal towards organic pollutants by removing active sites [59].

\subsection{Elemental analysis of biochars}

In comparison to most organic matter and many widely used criteria, some biochars have extremely high carbon contents (>80 wt \%). As a result, only a small amount of sample material needs to be weighed out for carbon content analysis.

This means that the measuring balance must be capable of correctly and precisely weighing in the low milligram range $(1-10 \mathrm{mg}$ ) (generally $1 \mathrm{~g}$ or better).

1) It also means that the biochar sample must be homogeneous enough for a representative sample to be analyzed. Most biochars contain a portion of highly concentrated aromatic carbon that is difficult to combust, which can result in poor peak form, chromatographic component separation, and carbon content underestimation.

2) Although the content of total organic carbon is typically the parameter of interest, many biochars contain calcium carbonate $(\mathrm{CaCO} 3)$ [53]. If total carbon is the parameter of interest, inorganic carbon must be extracted before analysis or the analysis should be corrected for the presence of inorganic carbon in the sample. The IBI guidelines for biochar product testing demand that total organic carbon, not total carbon, be recorded (IBI 2014). 
Since some biochars have very low $\mathrm{N}$ content, large samples must be used for analysis if accurate results at low abundance are needed. As a result, there may be difficulties ensuring quantitative combustion and complete degassing of atmospheric $\mathrm{N}$ from samples before study, as well as separating a small $\mathrm{N}$ peak from a much larger $\mathrm{CO}_{2}$ peak [60].

\subsection{Biochar stability soil}

The use of biochar on a large scale in soil has a significant impact on the amount of organic carbon (OC) in the soil.

The impact of biochar on composition and content of OC, on the other hand, is yet to be determined. In sandy soil supplemented with BC formed from manure at low temperature, both limited biochar stability and biochar-induced substantial positive priming effect upon OC mineralization have been typically found. Biochar's stable OC was made up of aromatic OC as well as OC components stabilized by soil minerals.

Biochar primarily promoted the production of macro-aggregates, which has been more pronounced in clayey soil supplemented with manure-based low-temperature-biochar[61]. The relation between biochar, organic material, and soil is illustrated in Figure (7).

\section{Some Literature Review}

A mixture of husk and cottonseed was used to produce biochar, where the thermal decomposition process was carried out at different temperatures, where temperatures are $200,350,500,650$ and $800{ }^{\circ} \mathrm{C}$ for 4 hours, in a box furnace with retort under the flow of nitrogen gas, and then kept in retort for the purpose of cooling overnight under the flow of nitrogen gas. Where the surface area of each sample is BET SA CH350 ${ }^{\circ} \mathrm{C} 4.7 \mathrm{~m} 2 / \mathrm{g}, \mathrm{CH} 500^{\circ} \mathrm{C} 0 \mathrm{~m} 2 / \mathrm{g}, \mathrm{CH} 650^{\circ} \mathrm{C} 34 \mathrm{~m} 2 / \mathrm{g}, \mathrm{CH} 800^{\circ} \mathrm{C} 322 \mathrm{~m} 2 / \mathrm{g}[62]$.

The remnants of the corn cob were used to manufacture biochar. The sample was dried at room temperature and then ground.To carry out the carbonization process, an inverted pressure reactor bar was used, where the reactor has been heated to the required temperature for 1.5 hours at a stirring rate of $150 \mathrm{ppm}$, and was cooled at room temperature, and the hydrochar has been obtained by filtration using a G3 filter, and dried for 24 hours at a temperature of $105^{\circ} \mathrm{C}$ [63].

Biochar was produced from corn straw, pyrolysis was done in a muffle furnace at $600^{\circ} \mathrm{C}$ temperature for 3 hours under nitrogen gas flow, and treated with KMnO4 Where different weight ratios were adopted 1:40 $(2.5 \%), 1: 10(10 \%)$ and $3: 5$ $(60 \%)$,It was dried at $80^{\circ} \mathrm{C}$, Where was the surface area BC $61.0(\mathrm{~m} 2 / \mathrm{g}), 2.5 \% \mathrm{MBC} 23.8(\mathrm{~m} 2 / \mathrm{g}), 10 \% \mathrm{MBC} 3.18(\mathrm{~m} 2 / \mathrm{g})$, $60 \% \mathrm{MBC} 2.28(\mathrm{~m} 2 / \mathrm{g})[64]$.

Corn stalks were used to produce biochar, where they were cut and dried at air temperature, and the pyrolysis process was carried out in a muffle oven for 2 hours at $400^{\circ} \mathrm{C}$, then it was treated with hydrochloric acid [65].

Sugar cane bagasse and orange peels were used to produce biochar. The materials were collected, washed thoroughly with tap water, dried at room temperature, then dried in the oven and then burned in an outer barrel with a tight lid. The carbonization was carried out in a well-lid inner barrel, as the BET Surface area to theSugar cane bagasse $92.30 \mathrm{~m}^{2} / \mathrm{g}, \mathrm{Total}$ porous volume, $0.04531 \mathrm{~m}^{3} / \mathrm{t}$, Average particle size, $65.0075 \mathrm{~nm}$. TheBET Surface area to theorange peels $0.21 \mathrm{~m}^{2} / \mathrm{g}$, total porous volume, $0.00016 \mathrm{~m}^{3} / \mathrm{t}$, average particle size $28773.72 \mathrm{~nm}$ [66].

Using pine fruit peels to prepare biochar, they have been washed and dried for $24 \mathrm{hrs}$ at a temperature of $100^{\circ} \mathrm{C}$ and were ground, then a thermal decomposition process was conducted for an hour at temperatures of 350,450 and $550{ }^{\circ} \mathrm{C}$, in a tubular furnace the oxygen was limited. Where was the surface area of each, the BET surface area $\mathrm{BC} 350 \quad 0.82\left(\mathrm{~m}^{2} / \mathrm{g}\right), \mathrm{BC} 450$ $1.29\left(\mathrm{~m}^{2} / \mathrm{g}\right)$, BC550 $228.11\left(\mathrm{~m}^{2} / \mathrm{g}\right)[67]$.

Table 3: Surface area as temperature [69]

\begin{tabular}{cc}
\hline Sample & BET $\left(\mathbf{m}^{2} / \mathbf{g}\right)$ \\
\hline H220 & 3.2 \\
H240 & 5.3 \\
H260 & 3.5 \\
H280 & 2.1 \\
P350 & 1.8 \\
P500 & 3.3 \\
P650 & 21.7 \\
P800 & 122.6 \\
\hline
\end{tabular}

Table 4: $\quad$ Surface area as temperature [70]

\begin{tabular}{ccc}
\hline Samples & BET $\mathbf{~ m}^{\mathbf{2}} / \mathbf{g}$ & Pore volume $\mathbf{~ c m}^{\mathbf{3}} / \mathbf{g}$ \\
\hline CS & 6 & 0.0125 \\
$200-$ Air & 12 & 0.020 \\
$200-\mathrm{N}_{2}$ & 13 & 0.014 \\
$250-$ Air & 12 & 0.024 \\
$250-\mathrm{N}_{2}$ & 6.5 & 0.012 \\
$300-$ Air & 9 & 0.019 \\
$300-\mathrm{N}_{2}$ & 7 & 0.015 \\
$500-\mathrm{N}_{2}$ & 6.5 & 0.016
\end{tabular}


Pine wood was used to manufacture biochar, where it was dried in a $105{ }^{\circ} \mathrm{C}$ oven, then the sample was placed in a hastelloy autoclave parr reactor. At $400{ }^{\circ} \mathrm{C}$ for half an hour, then it was cooled, washed and dried in the oven at $105^{\circ} \mathrm{C}[68]$.

Rice husk was used to manufacture biochar, where it was dried for more than 24 hours at a temperature of $65^{\circ} \mathrm{C}$, the carbonization process was carried out in the autoclave reactor at temperatures of $220,240,260$, and $280{ }^{\circ} \mathrm{C}$. For an hour under self-pressure with stirring by a magnetic stirrer, the hydrochar are dried for 24 hours at a temperature of $65^{\circ} \mathrm{C}$. The pyrolysis process was performed in a tubular reactor at temperatures of $350,500,650$, and $800^{\circ} \mathrm{C}$ then it is cooled at room temperature. Table(3)shows the surface area for each temperature [69].

Corn Stover was used to manufacture biochar, where it was dried at a temperature of $105{ }^{\circ} \mathrm{C}$, the sample was placed in a tube oven in nitrogen gas or air for half an hour at temperatures of 200,250 , and $300^{\circ} \mathrm{C}$. Table(4)shows the surface area for each temperature [70].

The switch herb was used to manufacture biochar, where it was washed and dried at $60{ }^{\circ} \mathrm{C}$. Thermal decomposition was performed in a muffle oven for one hour at temperatures of $600^{\circ} \mathrm{C}$ and $900^{\circ} \mathrm{C}$ when oxygenation is limited with the flow of nitrogen gas, it is then cooled. Where was the surface area of each, BET SA SB600 $\left(\mathrm{m}^{2} / \mathrm{g}\right)-255.8$, BET SA SB900 641.6 [71].

Chicken manure was used to prepare biochar, where it has been dried in the oven for 12 hours at $100^{\circ} \mathrm{C}$ it was ground well, then the pyrolysis process has been carried out in a tube furnace under a flow of nitrogen gas for two hours at a temperature of $200^{\circ} \mathrm{C}$ to $600^{\circ} \mathrm{C}$ and then cooled at room temperature. Where the surface area of each BET surface area $100^{\circ} \mathrm{C}$ (under air oven) $21.30\left(\mathrm{~m}^{2} / \mathrm{g}\right), 200^{\circ} \mathrm{C}$ (under $\mathrm{N}_{2}$ gas - furnace) $35.10\left(\mathrm{~m}^{2} / \mathrm{g}\right), 300{ }^{\circ} \mathrm{C}$ (under $\mathrm{N}_{2}$ gas - furnace) $41.50\left(\mathrm{~m}^{2} / \mathrm{g}\right.$ ), $400^{\circ} \mathrm{C}($ under $\mathrm{N}_{2}$ gas - furnace) $66.70\left(\mathrm{~m}^{2} / \mathrm{g}\right), 500^{\circ} \mathrm{C}$ (under $\mathrm{N}_{2}$ gas - furnace) $68.80\left(\mathrm{~m}^{2} / \mathrm{g}\right), 600^{\circ} \mathrm{C}$ (under $\mathrm{N}_{2}$ gas - furnace) $54.20\left(\mathrm{~m}^{2} / \mathrm{g}\right.$ ) [72].

Cassava straw was used to prepare biochar, where it was burned well in the oven in the absence of oxygen for half an hour, then the thermal decomposition process began for 1.5 hours at a temperature of $200^{\circ} \mathrm{C}$ where different temperatures were used for thermal decomposition, where the surface area of cassava straw has been $2.46 \mathrm{~m}^{2} / \mathrm{g}$, and the pore diameter has been $3.37 \mathrm{~nm}[73]$.

The remnants of the corn cob were used to manufacture biochar, where they were collected, dried at room temperature, and then finely ground. The carbonization process was performed inParr stirred pressured reactor. At a temperature of $250{ }^{\circ} \mathrm{C}$ for two hours, then wash well with ethanol and water until a neutral $\mathrm{pH}$ is achieved. Then the activation phase begins, where the material is treated with phosphoric acid for a period of 24 hours at room temperature, and then it is inserted in a tube oven with continuous nitrogen gas flow for two hours at a temperature of $500{ }^{\circ} \mathrm{C}$ followed by cooling inside the gas, and then it is washed well until a neutral $\mathrm{pH}$ is achieved. Dry it in an oven for 8 hours $105{ }^{\circ} \mathrm{C}$,was BET surface Area680 ( $\mathrm{m}^{2} / \mathrm{g}$ ), Pore volume $0.65 \mathrm{~cm}^{3} / \mathrm{g}$ and biochar was also manufactured using zinc chloride instead of phosphoric acid with the same steps, where was BET surface Area790 $\left(\mathrm{m}^{2} / \mathrm{g}\right)$, Pore volume $0.74 \mathrm{~cm}^{3} / \mathrm{g}[74]$.

\section{Applications of Biochar in Agriculture: Enhancing Soil and Compost Properties}

Globally, soil depletion is a major concern in agriculture.Researchers proposed applying biochar to deteriorated soils to fix this burgeoning problem in order to improve its consistency.Some of the ways biochar can aid in the improvement of soil quality include:

1. -Increasing soil structure

2. -Increased retention and aggregation of water

3. -Reducing acidity

4. -Decreasing the emission of nitrous oxide

5. -Enhancing Porosity

6. -Nitrogen leaching control

7. -Enhancement of electrical conductivity

8. -Enhancing microbial properties

As it decreases greenhouse gas emissions and avoids the depletion of nutrients in the compost, Biochar is also found to be useful for composting. It also encourages microbial development, which accelerates the process of composting in turn. Plus, it helps to minimize the loss of ammonia, bulk density and odor of the compost [75].

\subsection{The role of biochar in sequestering carbon and mitigation of the climate change}

The production of biochar is a carbon-negative process, meaning that $\mathrm{CO}_{2}$ in the atmosphere is actually reduced. The unstable carbon in the decay plant material is transformed into a stable form of carbon in the process of producing biochar, which is then deposited in biochar. As biochar is added to soil, for possibly hundreds or thousands of years, it preserves the carbon in a safe location. In fact, if they were left to decompose naturally, the feed stocks used for bio charging would release higher levels of carbon dioxide to the atmosphere. BC technology gradually lowers carbon dioxide in atmosphere through heating the feedstock and converting their carbon content to a stable structure which does not react to oxygen. By enriching the soils and decreasing the necessity for chemical fertilizers, which in turn decreases the emissions of the greenhouse gas, Biochar also contributes to climate change mitigation. The increased fertility of the soil also promotes plant growth that absorbs carbon dioxide. Biochar has many advantages for both the environment and agricultural systems, making it a promising method for regenerative farming [76]. 


\subsection{Biochar improve soil quality}

Utilizing a range of applicationspreparationandrates methods, Biochar is used for agricultural soils. Particular soil conditions and themattersutilizedfor producing the biochar would primarily depend on the rate of applications and preparations of the biochar. For inoculating it with nutrient elements and beneficial types, it is also advised to blend compost or other materialswithbiochar. According to how nutrient-rich or nutrient-depleted the soil is; the advised technique for applying BC can differ. One must at the beginningto consider the soil prior to using biochars in the farm or garden. Refer to the Recommendations for the International-Biochar-Initiative and Wakefield Biochar for more detail about how to apply biochar to various soil types [77].

\subsection{Biochar: an environmental solution}

Biochar may appear to be a simply structured material, however it can help assist an assortment of general issues all the while. For example, the interaction by which it's fabricated may help sequester a billion tons of carbon yearly and hold it in the dirt for millennia, where it's generally valuable.

During the creation of biochar, perfect and environmentally friendly power is delivered as a side-effect-this can be utilized as an option in contrast to consuming petroleum products, which has exacerbated a worldwide temperature alteration by adding ozone harming substances to the climate.

A portion of the other ecological advantages of biochar incorporate diminished groundwater contamination, filtration of water at a cheaper cost, decreased measures of waste and higher productivity for ranchers. This innovation additionally adds to food security by expanding crop yields and holding water in zones inclined to drought [78]

\subsection{Biochar as Permeable Reactive Barrier used in:}

1-Remediation of Groundwater Contaminated with heavy metals Ions,

The significance of this study is the sludge produced in enormous quantities from water supply system plant in treatment of aqueous solution (or groundwater) contaminated with lead ions. Both batch and continuous testing showed that this sludge has a high reactivity in the removal of lead ions and can therefore be appropriate for the permeable reactive barrier technique reactive contentBatch tests were performed with initial $\mathrm{pH}(3-6)$ operating conditions, contact period (about 120 min), sorbent dose $(0.03$ to $1 \mathrm{~g} / 50 \mathrm{~mL})$ for initial lead concentrations varying from 50 to $500 \mathrm{mg} / \mathrm{L}$ at $200 \mathrm{rpm}$ agitation pace. The best values for these parameters are 5,1 hour, and $0.3 \mathrm{~g} / 50 \mathrm{~mL}$ at the initial50 $\mathrm{mg} / \mathrm{L}$ concentration, respectively, to achieve a maximum97 $\%$ elimination [78].

\section{Remediation groundwater contaminated with leachate spilled from sanitary landfil-l}

Utilization of penetrable-receptive barrier (PRB) innovation of the waterworks sludge's side-effect created from the water supply treatments plants for remediating recreated groundwater dirtied with leachate spilled from the cleaning landfills. To clarify the relationship, leachate polluted with cadmium $(\mathrm{Cd}(\mathrm{II}))$, bunch sorption tests were performed (Cd(II)), Nitrogen alkali $\left(\mathrm{NH}_{3}-\mathrm{N}\right)$ or disintegrated natural matter Chemical oxygen demand (COD) and slime from waterworks. The multi-layered sorbent bed being referred to have a great ability to cure a leachate polluted with $\mathrm{Cd}(\mathrm{II}), \mathrm{NH}_{3}-\mathrm{N}$, and COD [79].

\section{Conclusions}

This review provided background information on biochar technology, substrate use from various sources as miscanthus, switch grass, corn Stover, and sugarcane bagasse. Also illustrated, is the prepared method with different pyrolysis temperature. Biochar suitable to use in several way as soil remediation, and successes as permeable active barrier to maintain the groundwater from pollutant as heavy metal, and the leachate from landfall. Biochar is an excellent, environmentally safe, and cost-effective means of managing water and soil pollutants.

\section{Author contribution \\ All authors contributed equally to this work. \\ Funding}

This research received no specific grant from any funding agency in the public, commercial, or not-for-profit sectors.

Data availability statement

The data that support the findings of this study are available on request from the corresponding author.

Conflicts of interest

The authors declare that there is no conflict of interest.

\section{References}

[1] D. Solomon et al., Molecular signature and sources of biochemical recalcitrance of organic C in Amazonian Dark Earths, Geochim. Cosmochim. Acta., 71( 2007) 2285-2298. https://doi.org/10.1016/j.gca.2007.02.014

[2] J. Lehmann, COMMENTARY, 447( 2007 ) 10-11.

[3] J. F. Ponge et al., Ingestion of charcoal by the Amazonian earthworm Pontoscolex corethrurus: A potential for tropical soil fertility, Soil. Biol. Biochem., 38( 2006) 2008-2009. https://doi.org/10.1016/j.soilbio.2005.12.024 
[4] P. Lumina, M. P. Pavithra, K. Yeshwanth, and J. K. R, Carbon-di-Oxide Capturing Using Biochar and Converting Biomass into Carbon-di-Oxide Capturing Using Biochar and Converting Biomass into Biochar,10. January, 2010.

[5] F.H. AL Ani, Gh.Y. AL-Kindi and N.Kh, Al-Bidri, Diclofenac Removal from Wastewater by Iraqi Pillared Clay, Eng. Technol. J., 37(2019) 281-288. https://doi.org/10.30684/etj.37.2C.13

[6] D. Ghanim, Gh. Y. Al-Kindi and A. Kh. Hassan, Green synthesis of iron nanoparticles using black tea leaves extract as adsorbent for removing eriochrome blue-black B dye, Eng. Technol. J., 38(2020),1558-1569. http://dx.doi.org/10.30684/etj.v38i10A.1225

[7] S. T. Alnasrawy, G.Y Alkindi and T. M. Albayati, Removal of high concentration phenol from aqueous solutions by electrochemical technique, Eng. Technol. J., 39(2021)189-195. http://dx.doi.org/10.30684/etj.v39i2A.1705

[8] Y. Zhu, S. Tjokro Rahardjo, C. Valkenburg, L. Snowden-Swan, S. Jones, and M. Machinal, Techno-economic Analysis for the Thermochemical Conversion of Biomass to Liquid Fuels (U.S. DOE), Doe, 152, 2011.

[9] D. O'Connor et al., Sustainable in situ remediation of recalcitrant organic pollutants in groundwater with controlled release materials: A review, J. Control. Release., 283(200-213) 2018. https://doi.org/10.1016/j.jconrel.2018.06.007

[10] K. Crombie, O. Mašek, S. P. Sohi, P. Brownsort, and A. Cross, The effect of pyrolysis conditions on biochar stability as determined by three methods, GCB Bioenergy., 5(122-131) 2013. https://doi.org/10.1111/gcbb.12030

[11] X. Yang, S. Zhang, M. Ju, and L. Liu, Preparation and modification of biochar materials and their application in soil remediation, Appl. Sci., 9( 2019). https://doi.org/10.3390/app9071365

[12] F. Verheijen, S. Jeffery, A. C. Bastos, M. Van Der Velde, and I. Diafas, Biochar Application to Soils: A Critical Scientific Review of Effects on Soil Properties, Processes and Functions, 8, 2010.

[13] D. Chen, Z. Zheng, K. Fu, Z. Zeng, J. Wang, and M. Lu, Torrefaction of biomass stalk and its effect on the yield and quality of pyrolysis products, Fuel, 159( 2015)27-32. https://doi.org/10.1016/j.fuel.2015.06.078

[14] K. C. Choi, E. K. Lee, S. Y. Choi, and S. J. Park, Electrical and physical properties of magnetite-filled NBR,Polym., $27(2003) 40-45$.

[15] L. A. Metz, N. K. Meruva, S. L. Morgan, and S. R. Goode, UV laser pyrolysis fast gas chromatography/time-of-flight mass spectrometry for rapid characterization of synthetic polymers: Optimization of instrumental parameters, J. Anal. Appl. Pyrolysis., 71( 2004)327-341. https://doi.org/10.1016/s0165-2370(03)00091-3

[16] L. Tang and H. Huang, Plasma pyrolysis of biomass for production of syngas and carbon adsorbent, Energy and Fuels, 19(2005 )1174-1178. https://doi.org/10.1021/ef049835b

[17] S. Yaman, Pyrolysis of biomass to produce fuels and chemical feedstocks, Energy Convers. Manag., 45(2004)651-671. https://doi.org/10.1016/s0196-8904(03)00177-8

[18] R. Chatterjee et al., Effect of Pyrolysis Temperature on PhysicoChemical Properties and Acoustic-Based Amination of Biochar for Efficient CO2 Adsorption, Front. Energy Res., 8(2020)1-18, https://doi.org/10.3389/fenrg.2020.00085

[19] M. Ahmad et al., Biochar as a sorbent for contaminant management in soil and water: A review, Chemosphere, 99(19-33) https://doi.org/10.1016/j.chemosphere.2013.10.071

[20] M. M. Hassan and C. M. Carr, A critical review on recent advancements of the removal of reactive dyes from dyehouse effluent by ion-exchange adsorbents, Chemosphere, 209(2018) $201-219$. https://doi.org/10.1016/j.chemosphere.2018.06.043

[21] D. C. K. Ko, C. W. Cheung, K. K. H. Choy, J. F. Porter, and G. McKay, Sorption equilibria of metal ions on bone char, Chemosphere, 54( 2004 )273-281. https://doi.org/10.1016/j.chemosphere.2003.08.004

[22] W. S. Wan Ngah and M. A. K. M. Hanafiah, Removal of heavy metal ions from wastewater by chemically modified plant wastes as adsorbents: A review, Bioresour. Technol., 99(2008)3935-3948. https://doi.org/10.1016/j.biortech.2007.06.011

[23] J. Pan, J. Jiang, and R. Xu, Adsorption of Cr(III) from acidic solutions by crop straw derived biochars, J. Environ. Sci., 25( 2013)1957-1965. https://doi.org/10.1016/s1001-0742(12)60305-2

[24] R. kou Xu, S. cheng Xiao, J. hua Yuan, and A. zhen Zhao, Adsorption of methyl violet from aqueous solutions by the biochars derived from crop residues, Bioresour. Technol., 102( 2011)10293-10298. https://doi.org/10.1016/j.biortech.2011.08.089

[25] X. Xu, X. Cao, L. Zhao, H. Wang, H. Yu, and B. Gao, Removal of Cu, Zn, and Cd from aqueous solutions by the dairy manure-derived biochar, Environ. Sci. Pollut. Res., 20( 2013)358-368. https://doi.org/10.1007/s11356-012-0873-5

[26] L. Qian, B. Chen, and D. Hu, Effective alleviation of aluminum phytotoxicity by manure-derived biochar, Environ. Sci. Technol., 47(2013 )2737-2745. https://doi.org/10.1021/es3047872 
[27] M. Jia et al., Effects of $\mathrm{pH}$ and metal ions on oxytetracycline sorption to maize-straw-derived biochar, Bioresour. Technol., 136(2013) 87-93. https://doi.org/10.1016/j.biortech.2013.02.098

[28] M. Zhang, B. Gao, S. Varnoosfaderani, A. Hebard, Y. Yao, and M. Inyang, Preparation and characterization of a novel magnetic biochar for arsenic removal, Bioresour. Technol., 130( 2013)457-462. https://doi.org/10.1016/j.biortech.2012.11.132

[29] R. J. Smernik, J. A. Baldock, J. M. Oades, and A. K. Whittaker, Determination of T1 $\rho H$ relaxation rates in charred and uncharred wood and consequences for NMR quantitation, Solid State Nucl. Magn. Reson., 22( 2002)50-70 . https://doi.org/ 10.1006/snmr.2002.0064

[30] E. W. Murage, P. Voroney, and R. P. Beyaert, Turnover of carbon in the free light fraction with and without charcoal as determined using the 13C natural abundance method, Geoderma, 138(2007) 133-143. https://doi.org/ 10.1016/j.geoderma.2006.11.002

[31] S. M. Haefele et al., Effects and fate of biochar from rice residues in rice-based systems, F. Crop. Res., 121( 2011)430440. https://doi.org/10.1016/j.fcr.2011.01.014

[32] K. Hammes, R. J. Smernik, J. O. Skjemstad, and M. W. I. Schmidt, "Characterisation and evaluation of reference materials for black carbon analysis using elemental composition, colour, BET surface area and 13C NMR spectroscopy, Appl. Geochemistry, 23( 2008)2113-2122. https://doi.org/10.1016/j.apgeochem.2008.04.023

[33] J. T. Yu, A. M. Dehkhoda, and N. Ellis, Development of biochar-based catalyst for transesterification of canola oil, Energy and Fuels, 25( 2011) 337-344. https://doi.org/10.1021/ef100977d

[34] J. Lehmann, J. Gaunt, and M. Rondon, Bio-char sequestration in terrestrial ecosystems - A review, Mitig. Adapt. Strateg. Glob. Chang., 11( 2006)403-427. https://doi.org/10.1007/s11027-005-9006-5

[35] M. S. Hasan Khan Tushar, N. Mahinpey, A. Khan, H. Ibrahim, P. Kumar, and R. Idem, Production, characterization and reactivity studies of chars produced by the isothermal pyrolysis of flax straw, Biomass and Bioenergy, 37( 2012)97-105. https://doi.org/10.1016/j.biombioe.2011.12.027

[36] Y. Qiu, Z. Zheng, Z. Zhou, and G. D. Sheng, Effectiveness and mechanisms of dye adsorption on a straw-based biochar, Bioresour. Technol., 100( 2009) 5348-5351,. https://doi.org/10.1016/j.biortech.2009.05.054

[37] S. Cheng, J. H. Jang, B. A. Dempsey, and B. E. Logan, Efficient recovery of nano-sized iron oxide particles from synthetic acid-mine drainage (AMD) water using fuel cell technologies, Water. Res., 45(2011)303-307. https://doi.org/ 10.1016/j.watres.2010.07.054

[38] H. P. Boehm, Some aspects of the surface chemistry of carbon blacks and other carbons, Carbon N. Y., 32(1994) 759 769. https://doi.org/10.1016/0008-6223(94)90031-0

[39] H. Cohen-Ofri, R. Popovitz-Biro, and S. Weiner, Structural characterization of modern and fossilized charcoal produced in natural fires as determined by using electron energy loss spectroscopy, Chem. - A Eur. J., 13( 2007 ) 2306-2310. https://doi.org/ 10.1002/chem.200600920

[40] F. M. Pellera et al., Adsorption of $\mathrm{Cu}(\mathrm{II})$ ions from aqueous solutions on biochars prepared from agricultural by-products, J. Environ. Manage., 96(2012) 35-42. https://doi.org/10.1016/j.jenvman.2011.10.010

[41] S. Zhou, D. Mourant, C. Lievens, Y. Wang, C. Z. Li, and M. Garcia-Perez, Effect of sulfuric acid concentration on the yield and properties of the bio-oils obtained from the auger and fast pyrolysis of Douglas Fir, Fuel, 104(2013)536-546. https://doi.org/10.1016/j.fuel.2012.06.010

[42] H. Lu, W. Zhang, Y. Yang, X. Huang, S. Wang, and R. Qiu, Relative distribution of Pb2+ sorption mechanisms by sludge-derived biochar ,Water. Res., 46( 2012)854-862. https://doi.org/10.1016/j.watres.2011.11.058

[43] J. W. Lee et al., Characterization of biochars produced from cornstovers for soil amendment, Environ. Sci. Technol., 44(2010)7970-7974. https://doi.org/10.1021/es101337x.

[44] A. Swiatkowski, M. Pakula, S. Biniak, and M. Walczyk, Influence of the surface chemistry of modified activated carbon on its electrochemical behaviour in the presence of lead(II) ions, Carbon. N. Y., 42( 2004)3057-3069. https://doi.org/ 10.1016/j.carbon.2004.06.043

[45] S. E. Hale, K. Hanley, J. Lehmann, A. R. Zimmerman, and Gerard Cornelissen, Erratum: Effects of chemical, biological, and physical aging as well as soil addition on the sorption (Environmental Science and Technology (2011) 45 (1044510453)of pyrene to activated carbon and biochar, Environ. Sci. Technol., 46(2012)2479-2480. https://doi.org/10.1021/es3001097

[46] G. N. Kasozi, A. R. Zimmerman, P. Nkedi-Kizza, and B. Gao, Catechol and humic acid sorption onto a range of laboratory-produced black carbons (biochars), Environ. Sci. Technol., 44 (2010)6189-6195. https://doi.org/10.1021/es1014423 
[47] D. Angin, Effect of pyrolysis temperature and heating rate on biochar obtained from pyrolysis of safflower seed press cake, Bioresour. Technol., 128(2013)593-597. https://doi.org/10.1016/j.biortech.2012.10.150

[48] J. Harmsen and R. Naidu, Bioavailability as a tool in site management, J. Hazard. Mater., 261(2013)840-846. https://doi.org/ 10.1016/i.jhazmat.2012.12.044

[49] K. B. Cantrell, P. G. Hunt, M. Uchimiya, J. M. Novak, and K. S. Ro, Impact of pyrolysis temperature and manure source on physicochemical characteristics of biochar, Bioresour. Technol., 107(2012)419-428. https://doi.org/ 10.1016/j.biortech.2011.11.084

[50] Y. Gao et al., Preparation of high surface area-activated carbon from lignin of papermaking black liquor by $\mathrm{KOH}$ activation for Ni(II) adsorption, Chem. Eng. J., 217(201)3345-353. https://doi.org/10.1016/j.cej.2012.09.038

[51] Y. Qiu, X. Xiao, H. Cheng, Z. Zhou, and G. D. Sheng, Influence of environmental factors on pesticide adsorption by black carbon: pH and model dissolved organic matter, Environ. Sci.Technol., 43(2009) 4973-4978. https://doi.org/ $\underline{10.1021 / \mathrm{es} 900573 \mathrm{~d}}$

[52] P. Mitchell, T. Dalley, R. Helleur, Preliminary laboratory production andcharacterization of biochars from lignocellulosic municipal waste, J. Anal. Appl. Pyrol ., 99 (2013) 71-78. https://doi.org/10.1016/j.jaap.2012.10.025

[53] A. Enders, K. Hanley, T. Whitman, S. Joseph, J. Lehmann, Characterization ofbiochars to evaluate recalcitrance and agronomic performance, Bioresour. Technol., 114 (2012) 644-653. https://doi.org/10.1016/j.biortech.2012.03.022

[54] D. Aller, S. Bakshi, and D. A. Laird, Modified method for proximate analysis of biochars, J. Anal. Appl. Pyrolysis., 124 (2017)335-342. https://doi.org/10.1016/j.jaap.2017.01.012

[55] Kim WK, Shim T, Kim YS, Hyun S, Ryu C, Park YK, Jung J. Characterization of cadmium removal from aqueous solution by biochar produced from a giant Miscanthus at different pyrolytic temperatures. Bioresour Technol [Internet] 2013 Jun;138:266-70. https://doi.org/10.1016/j.biortech.2013.03.186

[56] Kilic M, Kirbiyik C, Cepeliogullar O, Putun A. Adsorption of heavy metal ions from aqueous solutions by bio-char, a byproduct of pyrolysis. Appl Surf Sci [Internet] 2013 Oct 15;283:856-62. https://doi.org/10.1016/j.apsusc.2013.07.033

[57] Jiang S, Huang L, Nguyen TA, Ok YS, Rudolph V, Yang H, Zhang D. Copper and zinc adsorption by softwood and hardwood biochars under elevated sulphate-induced salinity and acidic pH conditions. Chemosphere [Internet] 2016 Jan;142(201)64-71. https://doi.org/10.1016/j.chemosphere.2015.06.079

[58] Takaya CA, Fletcher LA, Singh S, Anyikude KU, Ross AB. Phosphate and ammonium sorption capacity of biochar and hydrochar from different wastes. Chemosphere [Internet] 2016 Feb;145(201)518-27. https://doi.org/ 10.1016/j.chemosphere.2015.11.052

[59] Peng P, Lang YH, Wang XM. Adsorption behavior and mechanism of pentachlorophenol on reed biochars: pH effect, pyrolysis temperature, hydrochloric acid treatment and isotherms. Ecol Eng [Internet] 2016 May;90(201)225-33. https://doi.org/ 10.1016/j.ecoleng.2016.01.039

[60] C. E. Brewer and R. C. L. D. a Brown, Biochar characterization and engineering, Grad. Teses Diss., p. 12284, 2012, [Online].

[61] LanfangHanKeSunYanYang'XinghuiXia'FangbaiLZhifengYang'BaoshanXing (2020), Biochar's stability and effect on the content, composition and turnover of soil organic carbon, GeodermaVolume 364, 114184

[62] M. Uchimiya, L. H. Wartelle, K. T. Klasson, C. A. Fortier, and I. M. Lima, Influence of pyrolysis temperature on biochar property and function as a heavy metal sorbent in soil, J. Agric. Food Chem., 59( 2011)2501-2510. https://doi.org/ 10.1021/jf104206c

[63] L. Zhang, Q. Wang, B. Wang, G. Yang, L. A. Lucia, and J. Chen, Hydrothermal carbonization of corncob residues for hydrochar production, Energy and Fuels, 29( 2015) 872-876. https://doi.org/10.1021/ef502462p

[64] Z. Song, F. Lian, Z. Yu, L. Zhu, B. Xing, and W. Qiu, Synthesis and characterization of a novel MnOx-loaded biochar and its adsorption properties for $\mathrm{Cu} 2+$ in aqueous solution, Chem. Eng. J., 242(2014)36-42. https://doi.org/ 10.1016/j.cej.2013.12.061

[65] P. Sun, C. Hui, R. A. Khan, J. Du, Q. Zhang, and Y. H. Zhao, Efficient removal of crystal violet using Fe3O4-coated biochar: The role of the Fe3O4 nanoparticles and modeling study their adsorption behavior, Sci. Rep., 5, No. July(2015)112. https://doi.org/10.1038/srep12638

[66] A. A. Abdelhafez and J. Li, Removal of $\mathrm{Pb}(\mathrm{II})$ from aqueous solution by using biochars derived from sugar cane bagasse and orange peel, J. Taiwan Inst. Chem. Eng., 61(2016)367-375. https://doi.org/10.1016/j.jtice.2016.01.005

[67] N. A. S. Mohammed, R. A. Abu-Zurayk, I. Hamadneh, and A. H. Al-Dujaili, Phenol adsorption on biochar prepared from the pine fruit shells: Equilibrium, kinetic and thermodynamics studies, J. Environ. Manage., 226( 2018)377-385. https://doi.org/10.1016/j.jenvman.2018.08.033 
[68] M. D. Huff, S. Marshall, H. A. Saeed, and J. W. Lee, Surface oxygenation of biochar through ozonization for dramatically enhancing cation exchange capacity, Bioresour. Bioprocess., 5( 2018). https://doi.org/10.1186/s40643-018-0205-9

[69] X. Jian et al., Comparison of characterization and adsorption of biochars produced from hydrothermal carbonization and pyrolysis, Environ. Technol. Innov., 10(2018)27-35. https://doi.org/10.1016/j.eti.2018.01.004

[70] L. Li, M. Yang, Q. Lu, W. Zhu, H. Ma, and L. Dai, Oxygen-rich biochar from torrefaction: A versatile adsorbent for water pollution control, Bioresour. Technol., 294( 2019)122142. https://doi.org/10.1016/j.biortech.2019.122142

[71] J. H. Park, J. J. Wang, Y. Meng, Z. Wei, R. D. DeLaune, and D. C. Seo, Adsorption/desorption behavior of cationic and anionic dyes by biochars prepared at normal and high pyrolysis temperatures, Colloids Surfaces A Physicochem. Eng. Asp., 572( 2019)274-282. https://doi.org/10.1016/j.colsurfa.2019.04.029

[72] P. Q. Thang, K. Jitae, B. L. Giang, N. M. Viet, and P. T. Huong, Potential application of chicken manure biochar towards toxic phenol and 2,4-dinitrophenol in wastewaters,J. Environ. Manage., 251(2019)109556. https://doi.org/ 10.1016/j.jenvman.2019.109556

[73] I. Ali et al., Biochar addition coupled with nitrogen fertilization impacts on soil quality, crop productivity, and nitrogen uptake under double-cropping system, Food. Energy. Secur., 9( 2020)1-20. https://doi.org/10.1002/fes3.208

[74] B. Wang, M. Ran, G. Fang, T. Wu, and Y. Ni, Biochars from lignin-rich residue of furfural manufacturing process for heavy metal ions remediation,Materials. Basel., 13( 2020). https://doi.org/10.3390/ma13051037

[75] Y. Ding et al., Biochar to improve soil fertility. A review, Agron. Sustain. Dev., 36( 2016). https://doi.org/10.1007/s13593-016-0372-Z.

[76] R. K. Y. M.R. Yadav, R. K. C.M. Parihar, N. Y. R. Bajiya, H. R. R.K. Meena, and D. K. Y. B. Yadav, Role of Biochar in Mitigation of Climate Change through Carbon Sequestration, Int. J. Curr. Microbiol. Appl. Sci., 6 ( 2017 )859-866. https://doi.org/10.20546/ijcmas.2017.604.107

[77] G. Agegnehu, A. K. Srivastava, and M. I. Bird, The role of biochar and biochar-compost in improving soil quality and crop performance: A review, Appl. Soil Ecol., 119, October 2016(2017)156-170. https://doi.org/10.1016/j.apsoil.2017.06.008

[78] A. A. H. Faisal, I. M. Ali, L. A. Naji, H. M. Madhloom, and N. Al-Ansari, Using different materials as a permeable reactive barrier for remediation of groundwater contaminated with landfill's leachate, Desalin. Water Treat., 175 (2020)152-163. https://doi.org/10.5004/dwt.2020.24890

[79] S. Nanda, A. K. Dalai, F. Berruti, and J. A. Kozinski, Biochar as an Exceptional Bioresource for Energy, Agronomy, Carbon Sequestration, Activated Carbon and Specialty Materials, Waste and Biomass Valorization, 7( 2016)201-235. 